University of Nebraska - Lincoln

DigitalCommons@University of Nebraska - Lincoln

\title{
$5-2008$
}

\section{Identification of Guanylate Cyclases and Related Signaling Proteins in Sperm Tail from Sea Stars by Mass Spectrometry}

\author{
Mia Nakachi \\ Keio University, Yokohama, Japan \\ Midori Matsumoto \\ Keio University, Yokohama, Japan \\ Philip M. Terry \\ University of Nebraska-Lincoln \\ Ronald L. Cerny \\ University of Nebraska-Lincoln \\ Hideaki Moriyama \\ University of Nebraska-Lincoln, hmoriyama2@unl.edu
}

Follow this and additional works at: https://digitalcommons.unl.edu/chemistrymoriyama

Part of the Biotechnology Commons, and the Chemistry Commons

Nakachi, Mia; Matsumoto, Midori; Terry, Philip M.; Cerny, Ronald L.; and Moriyama, Hideaki, "Identification of Guanylate Cyclases and Related Signaling Proteins in Sperm Tail from Sea Stars by Mass Spectrometry" (2008). Hideaki Moriyama Publications. 7.

https://digitalcommons.unl.edu/chemistrymoriyama/7

This Article is brought to you for free and open access by the Published Research - Department of Chemistry at DigitalCommons@University of Nebraska - Lincoln. It has been accepted for inclusion in Hideaki Moriyama Publications by an authorized administrator of DigitalCommons@University of Nebraska - Lincoln. 


\title{
Identification of Guanylate Cyclases and Related Signaling Proteins in Sperm Tail from Sea Stars by Mass Spectrometry
}

\author{
Mia Nakachi, ${ }^{1}$ Midori Matsumoto, ${ }^{1}$ Philip M. Terry, ${ }^{2}$ Ronald L. Cerny, ${ }^{2,3}$ \\ and Hideaki Moriyama 2,3,4
}

\footnotetext{
${ }^{1}$ Department of Biosciences and Informatics, Keio University, Hiyoshi, Kouhoku-ku, Yokohama 223-8522, Japan

${ }^{2}$ Center for Biotechnology, University of Nebraska-Lincoln, Hamilton Hall, Lincoln, NE 68588-0304, USA

${ }^{3}$ Department of Chemistry, University of Nebraska-Lincoln, Hamilton Hall, Lincoln, NE 68588-0304, USA

${ }^{4}$ Center for Environmental Health and Toxicology, University of Nebraska-Lincoln, Hamilton Hall, Lincoln, NE 68588-0304, USA Corresponding author - Hideaki Moriyama, hmoriyama2@unl.edu
}

\begin{abstract}
Marine invertebrates employ external fertilization to take the advantages of sexual reproduction as one of excellent survival strategies. To prevent mismatching, successful fertilization can be made only after going though strictly defined steps in the fertilization. In sea stars, the fertilization process starts with the chemotaxis of sperm followed by hyperactivation of sperm upon arriving onto the egg coat, and then sperm penetrate to the egg coat before achieving the fusion. To investigate whether the initiation of chemotaxis and the following signaling has species specificity, we conducted comparative studies in the protein level among sea stars, Asterias amurensis, A. forbesi, and Asterina pectinifera. Since transcription of messenger ribonucleic acid (mRNA) has been suppressed in gamete, the roles of sperm proteins during the fertilization cannot be investigated by examining the mRNA profile. Therefore, proteomics analysis by mass spectrometry was used in this study. In sea stars, upon receiving asteroidal sperm-activating peptide (asterosap), the receptor membrane-bound guanylate cyclases in the sperm tail trigger sperm chemotaxis. We confirmed the presence of membrane-bound guanylate cyclases in the three sea star species, and they all had the same structural domains including the extracellular domain, kinase-like domain, and guanylate cyclase domain. The majority of peptides recovered were from a-helices distributed on the solvent
\end{abstract}

side of the protein. More peptides were recovered from the intracellular domains. The transmembrane domain has not been recovered. The functions of the receptors seemed to be conserved among the species. Furthermore, we identified proteins that may be involved in the guanylate cyclase-triggered signaling pathway.

Keywords: Proteomics, Sea star, Sperm, Chemotaxis, Guanylate cyclase, Asterias amurensis

\section{Introduction}

The major advantage of sexual reproduction is the creation of diversity. With this process, organisms are able to have sufficient diversity to avoid the accumulation of deleterious spontaneous mutations. Fertilization is the key step in the entire process of development of new individuals, which is the fusion of gametes to form a new organism of the same species (Baccetti and Afzelius 1976; Afzelius 1992). However, the organisms that exercise external fertilization always include the risk of mismatch fertilization. To prevent this serious ill outcome, successful fertilization can be made only after going through strictly defined steps (Vacquier 1998). 


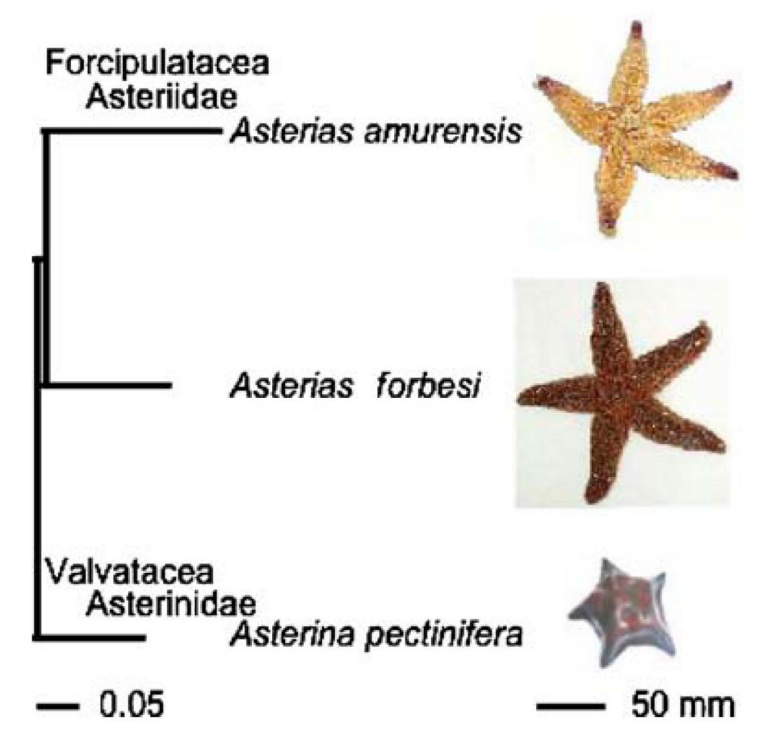

Figure 1. Taxonomy of the three sea star species used in this study. A phylogenetic reconstruction was made by the $16 \mathrm{~S}$ ribosomal gene. The bar indicates the branch length per substitution 0.05 .

The fertilization process is known to proceed very rapidly, and no transcription of messenger ribonucleic acid (mRNAs) occurs during this short time. It is known that transcription in sperm is repressed due to chromatin condensation (Hempel et al. 2006). Therefore, the roles of sperm proteins during the fertilization cannot be investigated simply by examining the mRNA profile in sperm (e.g., by expressed sequence tag [EST] sequencing). Alternatively, proteomics analysis should provide us more direct data on this complicated and very rapid process.

In sea stars Asterias amurensis and closely related $A$. forbesi (Figure 1), egg-originated components including a proteoglycan-like molecule, acrosome reaction-inducing substance (ARIS), sulfated steroid saponin CoARIS, and a 34 amino-acid peptide hormone asteroidal sperm-activating peptide (asterosap) cooperatively induce acrosome reaction (Matsui et al. 1986; Kawase et al. 2005), which is indispensable in the fertilization process. Among them, the interactions between the asterosap from the egg jelly and its receptor on the sperm tail provide the initial direction toward contacting the gametes. In this process, the asterosap functions as a chemoattractant to the sperm. The asterosap receptor, a membranebound guanylate cyclase, is specifically located in the sperm tail (Matsumoto et al. 2003; Shiba et al. 2006). The asterosap receptor has four structural domains including the extracellular domain receiving the asterosap, the transmembrane domain transmitting signals from the outside to the inside of the cell, the kinase-like domain having dephosphorylation upon stimulation from the outside, and the guanylate cyclase domain transmitting the secondary messenger, cyclic guanosine monophosphate (cGMP). The activated cGMP signaling leads to an increase in sperm intracellular $\mathrm{pH}$ (Kawase et al. 2005) and modulation of $\mathrm{Ca}^{2+}$ levels (Bohmer et al. 2005). Fig- ure 2 illustrates our hypothesized signaling pathway during the acrosome reaction process. After both of ARIS and asterosap bind to their receptors on the sperm membrane, resulted signals by these two ligands cooperatively induce acrosome reaction. ARIS binds to its unidentified receptor (ARIS-R in Figure 2). This binding leads to a small increase in intracellular $\mathrm{Ca}^{2+}$ through an unidentified $\mathrm{Ca}^{2+}$ channel-like activity. Asterosap binds to the guanylate cyclase extracellular domain and activates its intracellular catalytic domain to produce cGMP. Increased intracellular cGMP leads events such as membrane hyperpolarization and increases in intracellular $\mathrm{Ca}^{2+}$ and $\mathrm{pH}$ as reported (Matsumoto et al. 2003; Kawase et al. 2005). Candidate membrane proteins responsible for these events are the $\mathrm{K}^{+}$channel, the $\mathrm{K}^{+}$dependent $\mathrm{Na}^{+} / \mathrm{Ca}^{2+}$ exchanger (NCKX in Figure 2; Islam et al. 2006), and the $\mathrm{Na}^{+} / \mathrm{H}^{+}$exchanger (NHE in Figure 2). The Asterosap signal is transient because increased cGMP is quickly reduced by phosphodiesterase activity. ARIS signal and asterosap-induced $\mathrm{pH}$ increase cooperatively induce $\mathrm{Ca}^{2+}$ influx through the store-operated $\mathrm{Ca}^{2+}$ channel (SOC in Figure 2). The sustained $\mathrm{Ca}^{2+}$ increase by this influx finally induces acrosome reaction including exocytosis and actin polymerization. We have also reported that in sea stars, the specificity of the acrosome reaction induction is present at the subfamily level (Nakachi et al. 2006). However, more precise signaling mechanisms are yet to be elucidated.

To investigate whether the initiation of chemotaxis and the following signaling has species specificity, we established comparative studies in the protein level among sea stars A. amurensis, A. forbesi, and Asterina pectinifera. Our approaches to proteomics analysis of sperm tail-enriched fractions in sea stars: (1) demonstrate the feasibility of the tryptic mass spectrometry in comparing the three species by taking advantage of the high abundance of the asterosap receptor in sperm tail and (2) based on the confidence obtained 1, identify additional proteins in the sperm tail-enriched protein fraction to support our hypothesized signal transduction pathway (Figure 2).

\section{Materials and Methods}

\section{Animals and Gametes}

Three species of sea stars, A. amurensis, A. forbesi, and A. pectinifera, were used in this study (Figure 1). These sea stars were collected locally during their annual breeding seasons: March for A. amurensis in Tokyo Bay $\left(35^{\circ} 09^{\prime}\right.$ North $139^{\circ} 36^{\prime}$ East) and in Otsuchi Bay $\left(39^{\circ} 21^{\prime}\right.$ North $141^{\circ} 56^{\prime}$ East), Japan, June to July for A. forbesi in Woods Hole $\left(41^{\circ} 31^{\prime}\right.$ North $070^{\circ} 40^{\prime}$ West), MA, USA, and May for A. pectinifera in Tokyo Bay and September in Ohtsuchi Bay Japan (Nakachi et al. 2006). 


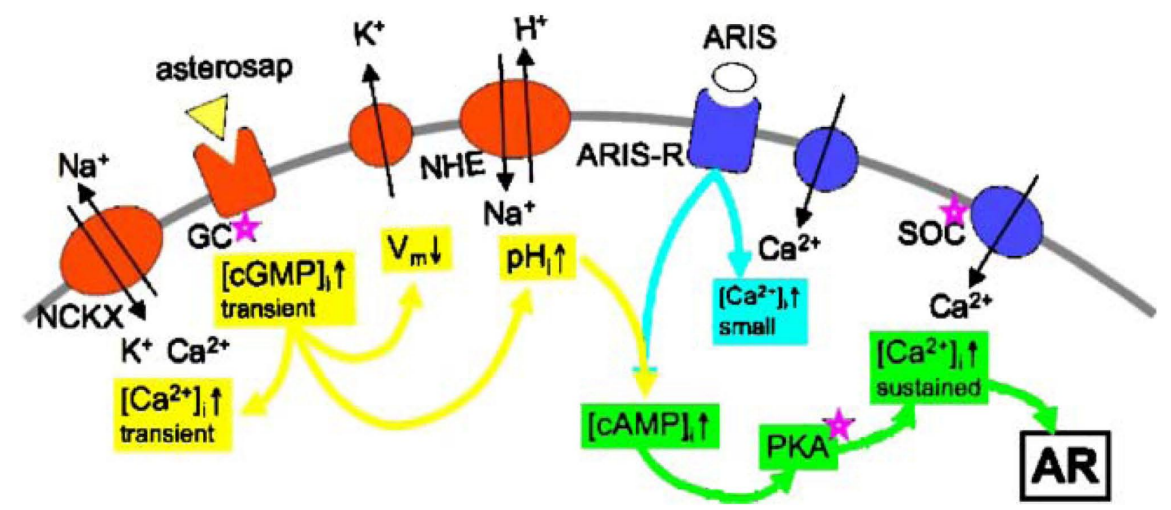

Figure 2. A model of signal transduction during the acrosome reaction in sea star sperm. Acrosome reaction-inducing substance (ARIS) and asteroidal sperm-activating peptide (asterosap) bind to their receptors. Signals by these two ligands cooperatively induce the acrosome reaction. ARIS binds to its unidentified receptor. This binding leads to a small increase in intracellular $\mathrm{Ca}^{2+}$ through an unidentified $\mathrm{Ca}^{2+}$ channel-like activity. Asterosap binds to the extracellular domain of guanylate cyclase and activates its intracellular catalytic domain to produce cGMP. Increased intracellular cGMP leads to events such as membrane hyperpolarization and increases in intracellular $\mathrm{Ca}^{2+}$ and $\mathrm{pH}$ (Kawase et al. 2005). Candidate membrane proteins responsible for these events are the $\mathrm{K}^{+}$channel, the $\mathrm{K}^{+}$-dependent $\mathrm{Na}^{+} / \mathrm{Ca}^{2+}$ exchanger $\left(\mathrm{NCKX}\right.$; Islam et al. 2006), the Na $/ \mathrm{H}^{+}$ exchanger (NHE), cAMP-dependent protein kinase (PKA), and store-operated $\mathrm{Ca}^{2+}$ channel (SOC). The asterosap signal is transient because the increased cGMP level is quickly reduced by phosphodiesterase activity.

\section{Preparation of Sperm Tail Proteins and Identification by Mass} Spectrometry

Sperm tails were separated as described previously (Nishigaki et al. 2000). The tail preparation was mixed with an equal volume of the $2 \times$ sample buffer $(4 \%$ sodium dodecyl sulfate [SDS], 20\% glycerol, 10\% Bromophenol blue, $10 \% \beta$-mercaptoethanol, and $125 \mathrm{mM}$ Tris, pH 6.8) and denatured by boiling for $5 \mathrm{~min}$ at $100^{\circ} \mathrm{C}$. The sample was separated by SDS-polyacrylamide gel electrophoresis (PAGE), cut into 20 gel fractions (Figure 3), digested with trypsin, and identified by the tandem mass spectrometry (MS/MS) using the published method (Rohila et al. 2006). The peak lists of the MS/MS data were generated by Distiller (Matrix Science, London, UK) using the charge state recognition and deisotoping with the other default parameters for quadrupole time-of-flight data. Database searches of the acquired MS/MS spectra were performed using Mascot (Matrix Science, v1.9.0). The MSDB database (a comprehensive, nonredundant protein sequence database maintained by the Proteomics Department at the Hammersmith Campus of Imperial College London, which combines entries from TrEMBL/SWISSPROT [Boeckmann et al. 2003; Wu et al. 2006] and GENBANK [Benson et al. 2007]; Release $02272005,1,942,918$ sequence entries) was used, and the taxonomy filter was set to "other metazoa" (excluding Chordata as well as Caenorhabditis elegans and Drosophila proteins). Search parameters used were: no restriction on protein molecular weight or $\mathrm{pI}$, enzymatic specificity set to trypsin, and methionine oxidation allowed as a variable peptide modification. Mass accuracy settings were $0.15 \mathrm{Da}$ for peptide mass and 0.12 Da for fragment ion masses. Significant protein hits that matched more than one peptide with $P<0.05$ were identified. In the same gel fraction, protein hits matching only redundant peptides with other protein hits of higher scores (given

as $S=-10 \log (P)$, where $S$ and $P$ are the score and the probability of the match, respectively) were removed. Mass search results on $A$. forbesi were posted at http:// npx001.unl.edu/database.html

\section{Phylogenetic Reconstruction}

After the multiple alignments performed using Clustal X (Thompson et al. 1997), phylogenetic reconstruction on 16S ribosomal RNA genes from $A$. amurensis (gi 57506693), A. forbesi (gi 82880473), and A. pectinifera (gi 1749374) was performed using Phylip (Felsenstein, J. 2005, PHYLIP [Phylogeny Inference Package] version

Figure 3. SDS-PAGE separation of the sperm tail-enriched fraction. The gel fragment 17 (marked by a star $\vec{i}$ ) contains a mass at $125 \mathrm{kDa}$, which corresponds to the molecular weight of the guanylate cyclase monomer. The major proteins identified in fractions that contain relatively dense bands were: $\beta$-tubulin in 5 , actin in $10, \beta$-tubulin in 12 , guanylate cyclase in 17 .

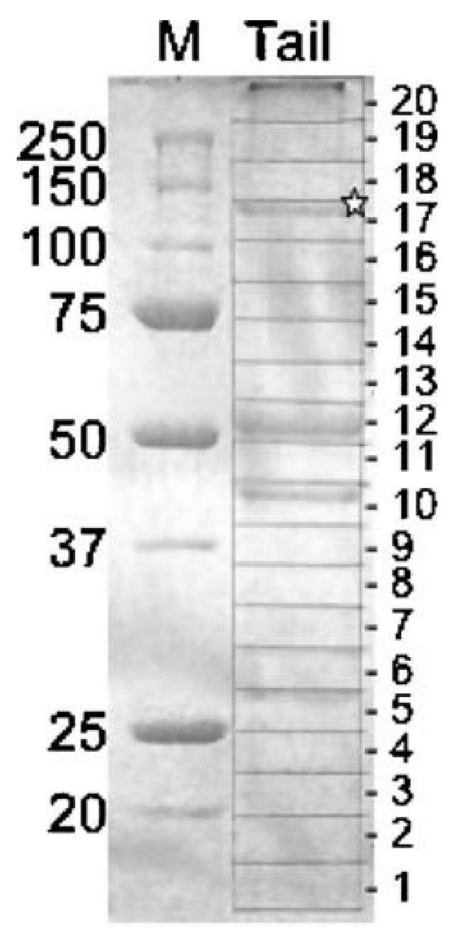


3.66 distributed by the author, Department of Genome Sciences, University of Washington, Seattle, WA, USA). Then phylogenetic trees were viewed using njplot (Perriere and Gouy 1996).

\section{Estimation of Solution Structure by Native Gel Electrophoresis}

Estimation of the molecular weight of the guanylate cyclase in the $A$. amurensis sperm tail was done by native PAGE. Sperm tail fractions were subjected treatments by either $5 \%(v / v) \beta$-mercaptoethanol or $4 \%(w / v)$ SDS for $5 \mathrm{~min}$ at room temperature. Then, samples were separated on native PAGE (5-15\%). Western blotting was performed using anti-guanylate cyclase as the first antibody and anti-rabbit IgG-horse radish peroxidase conjugate as the second antibody to detect guanylate cyclase in the tail fraction.

\section{Molecular Modeling}

The structural template for the guanylate cyclase from A. amurensis was searched using its primary sequence (Matsumoto et al. 1999). Modeling was performed with SWISS-MODEL (Kopp and Schwede 2006) and Phyre (Kelley et al. 2000). The extracellular, kinase-like, and guanylate cyclase domains were modeled using a hor- mone-bound atrial natriuretic peptide (ANP) receptor (NPR)-A extracellular domain (Protein Data Bank ID code 1t34; Ogawa et al. 2004), Raf proto-oncogene serine/threonine-protein kinase (1uwj; Wan et al. 2004), and type II adenylyl cyclase (1cul; Tesmer et al. 2000) as their templates, respectively. The root mean square of distances between the template (real structure) and target (model structure) were $1.4,0.5$, and $1.3 \AA\left(10^{-10} \mathrm{~m}\right)$ for extracellular, kinase-like, and guanylate cyclase domains, respectively. Structural mining was done using Swiss-PDB Viewer (Guex and Peitsch 1997). Graphical representations were prepared using PyMOL (DeLano Scientific, San Carlos, CA, USA).

\section{Results}

Mass Spectrometry of Sperm Tail Fraction from Asterias forbesi

To identify guanylate cyclase directly, we prepared the sperm tail fraction from $A$. forbesi. The fraction was analyzed by MS/MS. A Mascot search using sequences of the peptide fragments provided sufficient evidence that the sperm tail fraction from A. forbesi contained guanylate cyclase (Figs. 4 and S1).

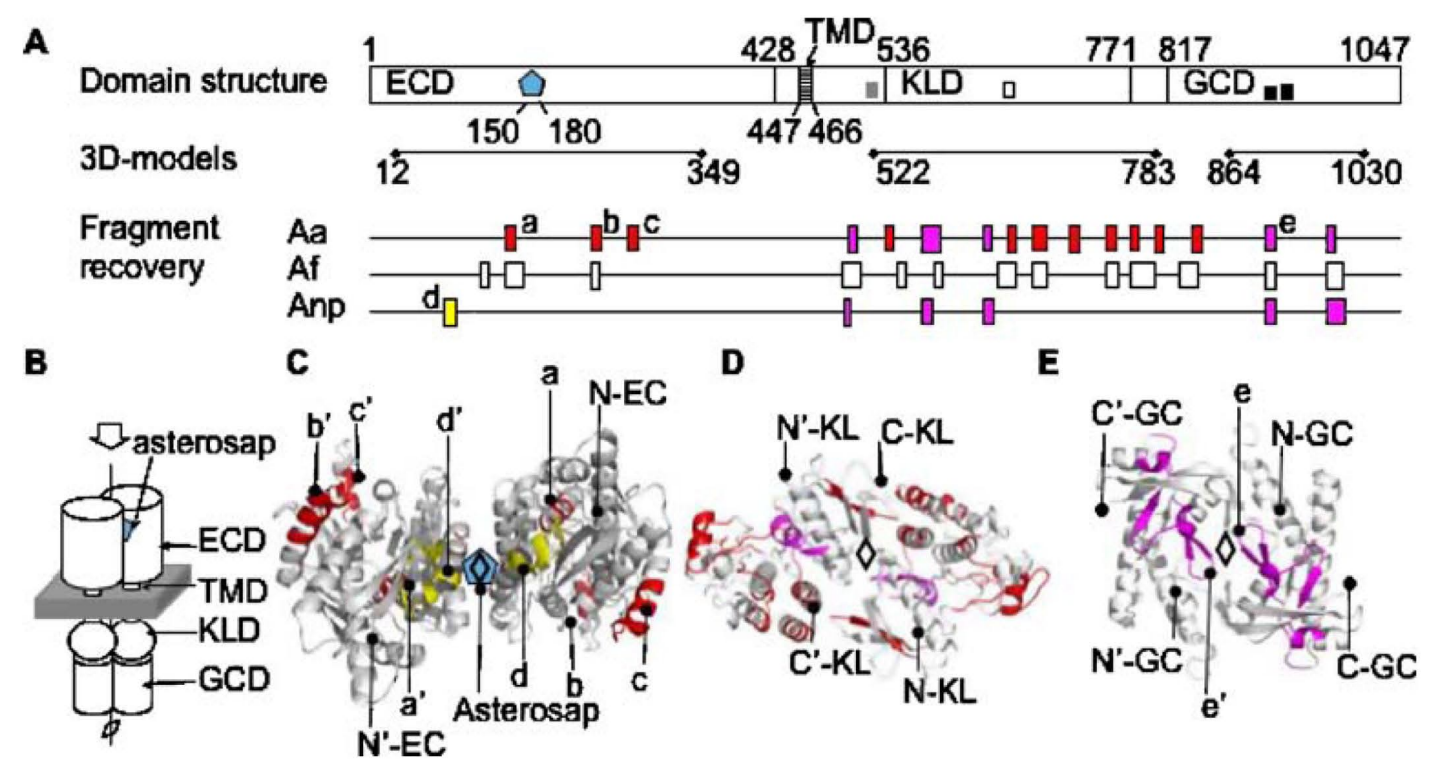

Figure 4. Location of identified peptides after the tandem MS. A The domain structure of the guanylate cyclase and peptide recovery. Functional domains (ECD extracellular domain, TMD transmembrane domain, KLD kinase-like domain, and GCD guanylate cyclase domain) and their amino acid positions on the A. amurensis guanylate cyclase are shown at the top. The light blue pentagon in the extracellular domain indicates the potential asterosap-binding site (also shown in the $\mathbf{B}$ and $\mathbf{C}$ ). The P-loop and the active segment in the kinase-like domain are indicated by the gray and white boxes. The black boxes in the guanylate cyclase domain indicate potential GTP-binding sites. Three-dimensional model coverages for the three domains are shown next by solid horizontal lines. Fragment recoveries are shown for A. amurensis (Aa), A. forbesi (Af), and A. pectinifera (Anp) with boxes (for detailed sequences, see Figure S1). Red boxes are for peptides found only in Aa, magenta boxes are for those found in both Aa and Anp, and yellow boxes are those for found in Anp only. Peptide numbers correspond to those shown in C, D, and E. B Schematic representation of guanylate cyclase as a homodimer. The gray area indicates the cell membrane. The arrow on the top indicates the viewpoint of the 3D-models in the C, D, and E. c, e, and e illustrate the 3D-models of the extracellular domain, kinase-like domain, and guanylate cyclase domain, respectively. All models are based on dimers. Peptide regions recovered in Aa and Anp are colored following A. Symmetry mates of the peptides $a-e$ are indicated as $a^{\prime}-e^{\prime}$. The diamonds indicate the twofold axes. Amino (N-) and carboxyl (C-) terminals of the models are indicated except for the ECD C-terminals (they are on the other sides of the figure). 
Table 1. Identified GC scores in gel fractions

\begin{tabular}{cr}
\hline Gel fraction & Score \\
\hline 5 & 218 \\
6 & 200 \\
7 & 60 \\
8 & 160 \\
9 & 566 \\
10 & 310 \\
12 & 63 \\
13 & 526 \\
14 & 779 \\
15 & 518 \\
16 & 592 \\
17 & 1,484 \\
18 & 500 \\
20 & 354 \\
\hline
\end{tabular}

The membrane-bound guanylate cyclase had the highest score at 1484, which was significantly higher than that of $\beta$-tubulin at 959 in the second place and adenosine triphosphate (ATP) synthase subunit at 551 in the third place. While the score does not indicate the quantity of the protein directly, the abundance of the guanylate cyclase was remarkable. Although the deduced molecular weight of guanylate cyclase is $124 \mathrm{kDa}$, it was detected in many gel fractions (Table 1). This is probably due to the abundance of the guanylate cyclase and the relatively harsh extraction treatment before SDS-PAGE. When obtained peptide fragments were compared to the entire mature amino acid sequence of the $A$. amurensis guanylate cyclase (1,047 amino acids), the total coverage of the peptides was $19 \%$. The peptides were distributed along the entire length of the protein (Figure 4A). The coverage rates of the extracellular domain, transmembrane domain, kinase-like domain, and guanylate cyclase domain were $11 \%, 0 \%, 25 \%$, and $24 \%$, respectively.

Only three peptide fragments were found from the extracellular domain (Figure 4A). The lower recovery of the extracellular domain may be due to the loss of peptide fragments from this region by catenation, which is the interlocking of many molecules into a lump. In fact, native PAGE of guanylate cyclases has highly catenated bands in a molecular weight higher than $500 \mathrm{kDa}$ (Figure 5). The extracellular domain has four cysteine residues out of 428 residues. A high molecular weight of the domain and structural complexity that allows allosteric movements similar to those reported in the NPRA extracellular domain may contribute to the catenation upon removal of SDS before the trypic digestion.

\section{Mass Spectrometry of Sperm Tail Fraction from Asterias amurensis and Asterina pectinifera}

We also prepared sperm tails from $A$. amurensis and A. pectinifera and performed MS/MS in the same manner as that used with $A$. forbesi. Many peptide fragments from both $A$. amurensis and $A$. pectinifera had a similar
Figure 5. Estimation of the molecular weight of the guanylate cyclase in the $A$. amurensis sperm tail by Native PAGE. Lanes: 1 , sperm tail without any treatment; 2, sperm tail with $\beta$-mercaptoethanol treatment; and 3, sperm tail with SDS treatment.

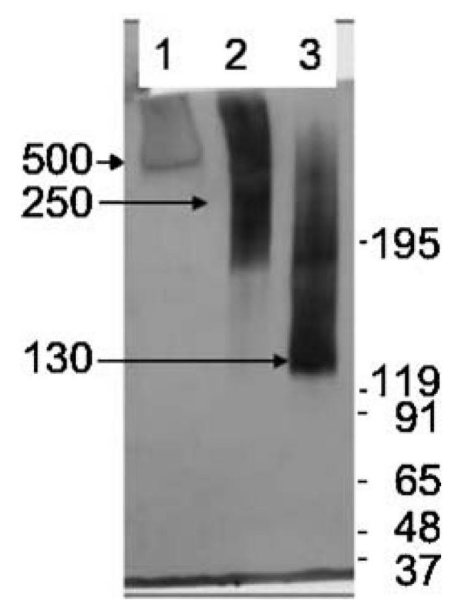

mass as those of the guanylate cyclase from A. forbesi. These matched fragments were distributed among the extracellular domain, kinase-like domain, and guanylate cyclase domain (Figs. 4A and S1). As expected, the recovered fragments in $A$. amurensis were nearly identical to those in $A$. forbesi. The total coverage of peptides from A. amurensis was $18 \%$, consistent with $19 \%$ for $A$. forbesi. However, each recovered peptide was slightly longer in $A$. forbesi than that of $A$. amurensis. In distantly related $A$. pectinifera (belonging to a different suborder and morphologically different; Figure 1), the total coverage of the peptides was only $8 \%$. This implies that the guanylate cyclase amino acid sequences of $A$. pectinifera and the two Asterias species are diverged enough, so that the compositions of the peptide fragments were drastically changed between the two groups of sea stars. It was remarkable since guanylate cyclases are in general considered to be highly conserved among divergent organisms (Fitzpatrick et al. 2006).

\section{Estimation of Solution Structure of Guanylate Cyclases}

The guanylate cyclase of $A$. amurensis had a molecular weight of approximately $500 \mathrm{kDa}$ in the native PAGE (Figure 5, lane 1) without any treatment. However, the molecular weight in the native PAGE was lowered to be approximately $250 \mathrm{kDa}$ with the treatment of $\beta$-mercaptoethanol, which reduces disulfide bonds formed within/between subunit(s) of the guanylate cyclases (Figure 5, lane 2). Unfolding the entire protein by the SDS treatment resulted in the band in front of guanylate cyclase at $130 \mathrm{kDa}$ (Figure 5, lane 3), which is almost consistent with the deduced molecular weight from the amino acid sequence of $124 \mathrm{kDa}$. While the present bands in the native PAGE were showing smears due to the polymorphic properties with catenations of transmembrane domains in addition to that of extracellular domain (Figure 4A), these observations indicated that the membrane-bound guanylate cyclases take dimers in the reduced condition as the molecular unit and take multimers in the native condition. 


\section{Functional Conservation in Guanylate Cyclases}

To observe the function and distribution of the peptide fragments on the 3D structure of the guanylate cyclase, we performed molecular modeling. Since the extracellular domain of $A$. amurensis is sufficiently similar to that of NPR-A (23\% identity), we modeled the structure of this domain using the ANP-bound NPR-A dimer as a template (Ogawa et al. 2004). The extracellular domain was built as a dimer after the dimer template structure. In addition, the molecular modeling of the kinase-like domain and guanylate cyclase domain was performed with assuming the dimer in the quaternary structure as described in "Materials and Methods."

Assuming the presence of a dimer structure like NPRA, the guanylate cyclase in A. amurensis could accept the asterosap in the center of the molecule (Figure $4 \mathrm{~B}$ and $\mathrm{C})$. The largest fragment recovered by the mass spectrometry in A. forbesi (the peptide a in Figure 4A and C) corresponded to the region including alpha-helices in the receptor that support the binding site of ANP. This fragment was also recovered in A. amurensis. A peptide identified in A. pectinifera (the peptide d in Figure 4A) corresponded to the hinge of the allosteric movement and dimerization region in NPR-A.

For the kinase activity, both the P-loop and the active segment have been reported to be functionally important (Wan et al. 2004). In our model of the guanylate cyclase from $A$. amurensis, the P-loop and the active segment correspond to Gln 522-Phe 525 and Asp 650-Lys 657, respectively (Figs. 3A and S2). However, only the active segments were identified in both $A$. amurensis and A. forbesi guanylate cyclases. In A. pectinifera, neither the
P-loop nor the active segment has been identified. It is interesting to note that in the guanylate cyclase domain, the peptide carrying potential guanosine triphosphate (GTP)-binding sites Glu 897-Met 905 has been identified in all species analyzed including A. pectinifera.

\section{Signal Transduction Pathway for Triggering Chemotaxis}

To assess the proteins present in the sea star sperm tail and to establish the hypothetical signaling pathway illustrated in Figure 2, more analysis was done in A. forbesi due to its longer peptide coverage.

All significant protein hits from the MS/MS ion search are listed in Table S1. We identified 74 hits for the tail-enriched fraction of $A$. forbesi. The number of protein hits was much smaller than 2,806 ESTs found in the testis of an ascidian, Ciona intestinalis (Inaba et al. 2002). This supports that the testis mRNA expression does not necessarily reflect the protein profile in the sperm. The classification of protein hits according to their biological process is shown in Figure 6.

\section{Discussion}

The results obtained in this report using mass spectrometry indicate that (1) the guanylate cyclase is an abundant sperm tail protein in A. amurensis, A. forbesi, and $A$. pectinifera and (2) some other proteins supporting our hypothesis of signal transduction exist in sperm tail.

The membrane-bound guanylate cyclase has been identified with a high score in sperm tail of each sea star species examined (Table S1 for A. forbesi), indicating its

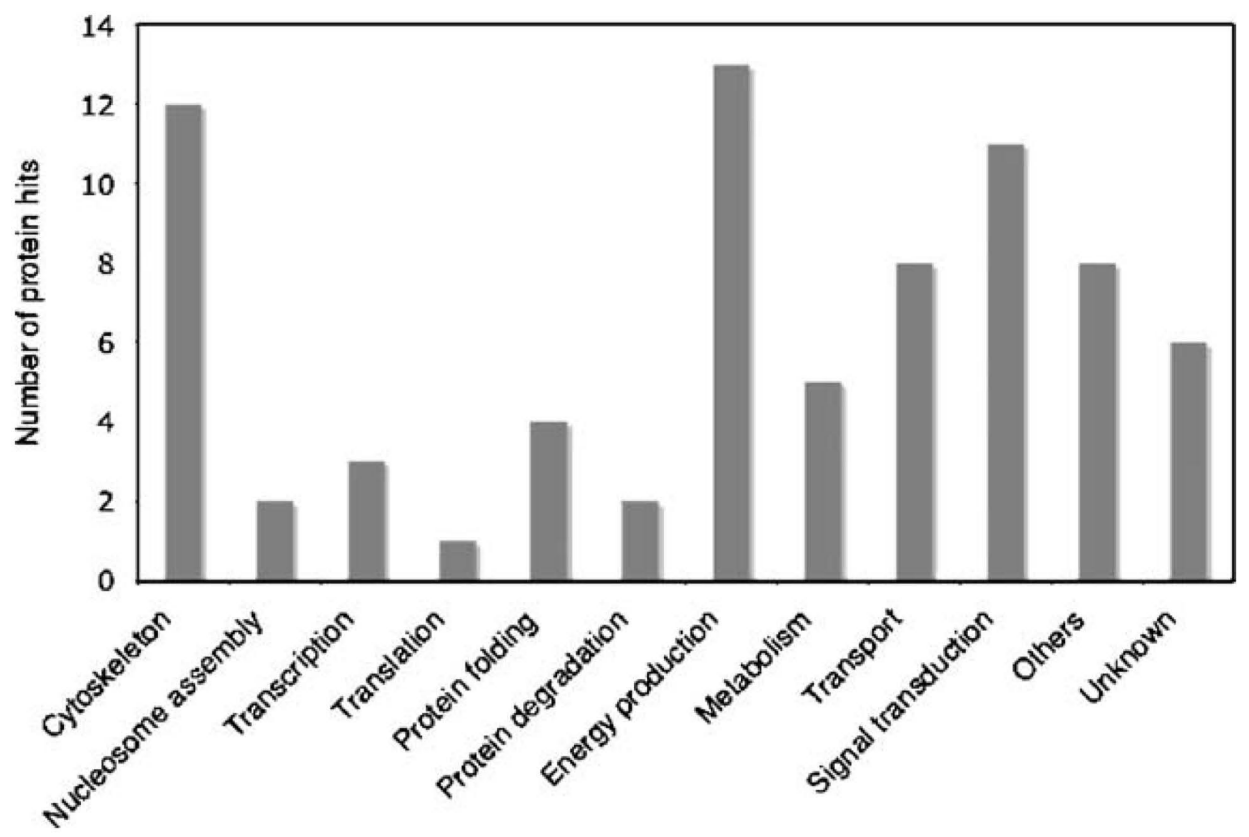

Figure 6. Functional classification of proteins identified from the sperm tail of A. forbesi by MS/MS. All protein hits are listed in Table S1. 
significant abundance in the sperm tail (Matsumoto et al. 2003). The abundance of guanylate cyclase may be required to allow the sperm to persist in chemotaxis, receiving signaling molecules one by one until reaching the egg. The guanylate cyclases share the similar primary sequence and presumably the functions including receiving an asterosap-like peptide and kinase-like and guanylate cyclase functions. The identification of the guanylate cyclase and its ligand in A. pectinifera would provide us further information to investigate its ligand reception mechanism. The complementary deoxyribonucleic acid cloning of guanylate cyclase from A. pectinifera is currently underway (data not shown).

Eleven $(15 \%)$ of the protein hits from $A$. forbesi were related to signal transduction (shown in bold-face in Table S1). Among them, the membrane-bound guanylate cyclase had the highest score, indicating its significant abundance in the sperm tail. Other signal transduction proteins identified are protein kinases, Rab (a small guanosine triphosphatase or GTPase involved in membrane traffic), calmodulin, transient receptor potential channel, and $G$ protein $\beta$-subunit. These proteins are candidates functioning downstream of the guanylate cyclase, triggered by signals leading to chemotaxis and/or the acrosome reaction.

There were other protein hits possibly functioning during the course of fertilization in sea stars. Bindin is the major protein in the acrosomal vesicle of sea urchins and mediates sperm-egg adhesion after the acrosome reaction. Although bindin is conserved widely in sea urchins, it has not been found in sea stars. We identified a bindin (in Table S1, the group "others," the hit against Q7Z0F7) and a proteasome (in Table S1, the group "protein degradation," the hit against Q7PYL5) in sea star sperm, these proteins potentially have roles in fertilization. The ubiquitin-proteasome system participates in the acrosome reaction of sea urchins (Matsumura and Aketa 1991) and humans (Morales et al. 2003) and in sperm penetration through the extracellular coat of the egg in ascidians (Takizawa et al. 1993; Sawada 2002; Sawada et al. 2002) and mammals (Sutovsky et al. 2004).

Many other hits with high scores in the sperm tail were cytoskeletal proteins such as tubulin and actin (Table S1) indicating a large quantity and functional importance of them. For example, tubulin is a major component of the axoneme, which is essential for the tail movement. ATP synthase also had hits with high scores, which is consistent with the importance of energy production in sperm.

Martinez-Heredia et al. (2006) identified 98 proteins in human sperm using 2D-gel and matrix-assisted laser desorption-ionization time-of-flight mass spectrometry. We identified 74 proteins in the sea star sperm tail. The difference in the number of proteins between human and sea stars could reflect the difference in their fertilization systems, where humans utilize interior fertiliza- tion, while external fertilization is used in sea stars. Alternatively, it might reflect the difference in the methods used in these studies. Additionally, our analysis only examined sperm tails and not the entire sperm.

\section{Acknowledgments}

We thank Dr. Kohei Homma and Ms. Brittney Schirber for their technical assistance. The mass spectrometry facility is supported in part by NIH Grant P20 RR15635 from the COBRE Program of the National Center for Research Resources, NCI Cancer Center Support Grant P30 CA36727, NIH grant RR015468-01, and the Nebraska Research Initiative.

\section{References}

Afzelius BA (1992) Section staining for electron microscopy using tannic acid as a mordant: a simple method for visualization of glycogen and collagen. Microsc Res Technol 21:65-72

Baccetti B, Afzelius BA (1976) The biology of the sperm cell. Monogr Dev Biol 10:1-254

Benson DA, Karsch-Mizrachi I, Lipman DJ, Ostell J, Wheeler DL (2007) GenBank. Nucleic Acids Res 35:D21-D25

Boeckmann B, Bairoch A, Apweiler R, Blatter MC, Estreicher A, Gasteiger E, Martin MJ, Michoud K, O'Donovan C, Phan I, Pilbout S, Schneider M (2003) The SWISS-PROT protein knowledgebase and its supplement TrEMBL in 2003. Nucleic Acids Res 31:365-370

Bohmer M, Van Q, Weyand I, Hagen V, Beyermann M, Matsumoto M, Hoshi M, Hildebrand E, Kaupp UB (2005) Ca2+ spikes in the flagellum control chemotactic behavior of sperm. Embo J 24:2741-2752

Fitzpatrick DA, O'Halloran DM, Burnell AM (2006) Multiple lineage specific expansions within the guanylyl cyclase gene family. BMC Evol Biol 6:26

Guex N, Peitsch MC (1997) SWISS-MODEL and the Swiss-PdbViewer: an environment for comparative protein modeling. Electrophoresis 18:2714-2723

Hempel LU, Rathke C, Raja SJ, Renkawitz-Pohl R (2006) In Drosophila, don juan and don juan like encode proteins of the spermatid nucleus and the flagellum and both are regulated at the transcriptional level by the TAF II80 cannonball while translational repression is achieved by distinct elements. Dev Dyn 235:1053-1064

Inaba K, Padma P, Satouh Y, Shin IT, Kohara Y, Satoh N, Satou Y (2002) EST analysis of gene expression in testis of the ascidian Ciona intestinalis. Mol Reprod Dev 62:431-445

Islam MS, Kawase O, Hase S, Minakata H, Hoshi M, Matsumoto $\mathrm{M}(2006) \mathrm{Na}(+) / \mathrm{Ca}(2+)$ exchanger contributes to asterosap-induced elevation of intracellular $\mathrm{Ca}(2+)$ concentration in starfish spermatozoa. Zygote 14:133-141

Kawase O, Minakata H, Hoshi M, Matsumoto M (2005) Asterosap-induced elevation in intracellular $\mathrm{pH}$ is indispensable for ARIS-induced sustained increase in intracellular $\mathrm{Ca} 2+$ and following acrosome reaction in starfish spermatozoa. Zygote 13:63-71 
Kelley LA, MacCallum RM, Sternberg MJ (2000) Enhanced genome annotation using structural profiles in the program 3D-PSSM. J Mol Biol 299:499-520

Kopp J, Schwede T (2006) The SWISS-MODEL Repository: new features and functionalities. Nucleic Acids Res 34: D315-D318

Martinez-Heredia J, Estanyol JM, Ballesca JL, Oliva R (2006) Proteomic identification of human sperm proteins. Proteomics 6:4356-4369

Matsui T, Nishiyama I, Hino A, Hoshi M (1986) Induction of the acrosome reaction in starfish. Develop Growth Differ 28:339-348

Matsumoto M, Briones AV, Nishigaki T, Hoshi M (1999) Sequence analysis of cDNAs encoding precursors of starfish asterosaps. Dev Genet 25:130-136

Matsumoto M, Solzin J, Helbig A, Hagen V, Ueno S, Kawase O, Maruyama Y, Ogiso M, Godde M, Minakata H, Kaupp UB, Hoshi M, Weyand I (2003) A sperm-activating peptide controls a cGMP-signaling pathway in starfish sperm. Dev Biol 260:314-324

Matsumura K, Aketa K (1991) Proteasome (multicatalytic proteinase) of sea urchin sperm and its possible participation in the acrosome reaction. Mol Reprod Dev 29:189-199

Morales P, Kong M, Pizarro E, Pasten C (2003) Participation of the sperm proteasome in human fertilization. Hum Reprod 18:1010-1017

Nakachi M, Moriyama H, Hoshi M, Matsumoto M (2006) Acrosome reaction is subfamily specific in sea star fertilization. Dev Biol 298:597-604

Nishigaki T, Chiba K, Hoshi M (2000) A 130-kDa membrane protein of sperm flagella is the receptor for asterosaps, sperm-activating peptides of starfish Asterias amurensis. Dev Biol 219:154-162

Ogawa H, Qiu Y, Ogata CM, Misono KS (2004) Crystal structure of hormone-bound atrial natriuretic peptide receptor extracellular domain: rotation mechanism for transmembrane signal transduction. J Biol Chem 279:28625-28631

Perriere G, Gouy M (1996) WWW-query: an on-line retrieval system for biological sequence banks. Biochimie 78:364-369

Rohila JS, Chen M, Chen S, Chen J, Cerny R, Dardick C, Canlas P, Xu X, Gribskov M, Kanrar S, Zhu JK, Ronald P, Fromm
ME (2006) Protein-protein interactions of tandem affinity purification-tagged protein kinases in rice. Plant J 46:1-13

Sawada H (2002) Ascidian sperm lysin system. Zool Sci 19:139-151

Sawada H, Sakai N, Abe Y, Tanaka E, Takahashi Y, Fujino J, Kodama E, Takizawa S, Yokosawa H (2002) Extracellular ubiquitination and proteasome-mediated degradation of the ascidian sperm receptor. Proc Natl Acad Sci USA 99:1223-1228

Shiba K, Tagata T, Ohmuro J, Mogami Y, Matsumoto M, Hoshi M, Baba SA (2006) Peptide-induced hyperactivation-like vigorous flagellar movement in starfish sperm. Zygote 14:23-32

Sutovsky P, Manandhar G, McCauley TC, Caamano JN, Sutovsky M, Thompson WE, Day BN (2004) Proteasomal interference prevents zona pellucida penetration and fertilization in mammals. Biol Reprod 71:1625-1637

Takizawa S, Sawada H, Someno T, Saitoh Y, Yokosawa H, Hoshi M (1993) Effects of protease inhibitors on binding of sperm to the vitelline coat of ascidian eggs: implications for participation of a proteasome (multicatalytic proteinase complex). J Exp Zool 267:86-91

Tesmer JJ, Dessauer CW, Sunahara RK, Murray LD, Johnson RA, Gilman AG, Sprang SR (2000) Molecular basis for P-site inhibition of adenylyl cyclase. Biochemistry 39:14464-14471

Thompson JD, Gibson TJ, Plewniak F, Jeanmougin F, Higgins DG (1997) The CLUSTAL_X windows interface: flexible strategies for multiple sequence alignment aided by quality analysis tools. Nucleic Acids Res 25:4876-4882

Vacquier VD (1998) Evolution of gamete recognition proteins. Science 281:1995-1998

Wan PT, Garnett MJ, Roe SM, Lee S, Niculescu-Duvaz D, Good VM, Jones CM, Marshall CJ, Springer CJ, Barford D, Marais R (2004) Mechanism of activation of the RAF-ERK signaling pathway by oncogenic mutations of B-RAF. Cell 116:855-867

Wu CH, Apweiler R, Bairoch A, Natale DA, Barker WC, Boeckmann B, Ferro S, Gasteiger E, Huang H, Lopez R, Magrane M, Martin MJ, Mazumder R, O'Donovan C, Redaschi N, Suzek B (2006) The Universal Protein Resource (UniProt): an expanding universe of protein information. Nucleic Acids Res 34:D187-D191

\section{Supplemental materials (Table S1 \& Figure S1) follow.}


Table S1. The list of significant protein hits by MS/MS from Asterias forbesi sperm tail.

\begin{tabular}{|c|c|c|c|c|c|}
\hline Biological process & & Accession No. & Protein description & Mass/Da & Score \\
\hline \multirow[t]{12}{*}{ Cytoskeleton } & \multirow[t]{3}{*}{ Actin } & P12716 & Pisaster ochraceus Actin, cytoplasmic & 42164 & 785 \\
\hline & & Q6PPI5 & Homalodisca coagulata Putative muscle actin & 42158 & 589 \\
\hline & & Q7M3Y6 & Pisaster ochraceus Actin, cytoplasmic & 16929 & 48 \\
\hline & \multirow[t]{4}{*}{ Tubulin } & Q7YZK9 & Ephydatia cooperensis Beta-tubulin [fragment] & 43543 & 959 \\
\hline & & Q6QA77 & Laodelphax striatellus Alpha 2-tubulin & 50635 & 812 \\
\hline & & Q27122 & Urechis caupo Alpha-tubulin & 50742 & 774 \\
\hline & & Q8MVT9 & $\begin{array}{l}\text { Strongylocentrotus droebachiensis Alpha-tubulin } 2 \\
\text { [fragment] }\end{array}$ & 44652 & 149 \\
\hline & \multirow[t]{4}{*}{ Dynein } & P23098 & Tripneustes gratilla Dynein beta chain, ciliary & 515561 & 349 \\
\hline & & Q16959 & $\begin{array}{l}\text { Anthocidaris crassispina Dynein intermediate chain 2, } \\
\text { ciliary }\end{array}$ & 79659 & 80 \\
\hline & & Q27803 & $\begin{array}{l}\text { Tripneustes gratilla Dynein heavy chain isotype 3A } \\
\text { [fragment] }\end{array}$ & 122210 & 63 \\
\hline & & Q26630 & $\begin{array}{l}\text { Strongylocentrotus purpuratus } 33 \mathrm{kDa} \text { inner dynein arm } \\
\text { light chain, axonemal }\end{array}$ & 29942 & 57 \\
\hline & Others & O46178 & Strongylocentrotus purpuratus Radial spokehead & 62856 & 83 \\
\hline \multirow[t]{2}{*}{$\begin{array}{l}\text { Nucleosome } \\
\text { assembly }\end{array}$} & & O61423 & Notocrater houbricki Histone H3 [fragment] & 10347 & 37 \\
\hline & & P35068 & Tigriopus californicus Histone H2B.1/H2B.2 & 13512 & 117 \\
\hline \multirow[t]{3}{*}{$\begin{array}{l}\text { Regulation of } \\
\text { Transcription }\end{array}$} & & Q7PU25 & Anopheles gambiae ENSANGP00000000462 & 18983 & 33 \\
\hline & & Q9XYT7 & $\begin{array}{l}\text { Cassiopea xamachana } \text { Scox-3 homeodomain protein } \\
\text { [fragment] }\end{array}$ & 31308 & 39 \\
\hline & & Q7QMF2 & Anopheles gambiae AgCP3095 [fragment] & 46727 & 43 \\
\hline Translation & & Q7PVR3 & Anopheles gambiae ENSANGP00000016885 [fragment] & 38840 & 31 \\
\hline \multirow[t]{4}{*}{ Protein folding } & & Q6QR01 & Chiromantes haematocheir Hsp-90 & 82798 & 103 \\
\hline & & Q8ISB1 & Panagrellus redivivus Heat shock protein 70-C & 72874 & 127 \\
\hline & & Q7Q1P2 & Anopheles gambiae EbiP4677 [fragment] & 53459 & 65 \\
\hline & & Q7PGM0 & Anopheles gambiae ENSANGP00000024201 [fragment] & 60081 & 70 \\
\hline \multirow[t]{2}{*}{$\begin{array}{l}\text { Protein } \\
\text { degradation }\end{array}$} & & Q75PZ3 & $\begin{array}{l}\text { Brugia malayi Mitochondria processing peptidase subunit } \\
\text { beta }\end{array}$ & 53839 & 57 \\
\hline & & Q7PYL5 & Anopheles gambiae AgCP11949 [fragment] & 26495 & 50 \\
\hline \multirow[t]{13}{*}{ Energy production } & Glycolysis & Q75PQ3 & Antheraea yamamai Fructose 1,6-bisphosphate aldolase & 40026 & 84 \\
\hline & \multirow[t]{4}{*}{ TCA cycle } & Q7PYE7 & Anopheles gambiae $\mathrm{AgCP} 12505$ [fragment] & 37016 & 91 \\
\hline & & Q7PV48 & Anopheles gambiae ENSANGP00000015768 & 52858 & 40 \\
\hline & & Q7QDV0 & Anopheles gambiae AgCP10712 [fragment] & 75823 & 227 \\
\hline & & Q86GF8 & Antheraea yamamai Hypothetical protein precursor & 86143 & 32 \\
\hline & \multirow[t]{6}{*}{ Electron transport } & S70599 & Asterina pectinifera Cytochrome c oxidase subunit 2 & 26228 & 171 \\
\hline & & Q7PMH3 & Anopheles gambiae ENSANGP00000012416 [fragment] & 54025 & 149 \\
\hline & & Q7PKU3 & Anopheles gambiae ENSANGP00000025162 [fragment] & 46913 & 64 \\
\hline & & Q7PRW3 & Anopheles gambiae ENSANGP00000019428 & 32157 & 54 \\
\hline & & Q7PTG6 & Anopheles gambiae ENSANGP00000021821 [fragment] & 50343 & 35 \\
\hline & & Q7PY23 & Anopheles gambiae AgCP12501 [fragment] & 29738 & 31 \\
\hline & \multirow[t]{2}{*}{$\begin{array}{l}\text { ATP synthesis } \\
\text { coupled proton } \\
\text { transport }\end{array}$} & Q7PQ05 & Anopheles gambiae ENSANGP00000009989 [fragment] & 59427 & 481 \\
\hline & & Q6PTS0 & Asterina miniata ATP synthase beta subunit [fragment] & 45971 & 551 \\
\hline
\end{tabular}




\begin{tabular}{|c|c|c|c|c|c|}
\hline \multirow[t]{5}{*}{ Metabolism } & \multirow{3}{*}{$\begin{array}{l}\text { Amino acid } \\
\text { metabolism }\end{array}$} & P18294 & Strongylocentrotus purpuratus Creatine kinase, flagellar & 132383 & 144 \\
\hline & & Q6BDZ3 & $\begin{array}{l}\text { Siphonosoma sp. ST01 Creatine kinase, mitochondrial } \\
\text { [fragment] }\end{array}$ & 42971 & 78 \\
\hline & & Q7PPE1 & Anopheles gambiae ENSANGP00000021599 [fragment] & 57517 & 43 \\
\hline & $\begin{array}{l}\text { Nucleic acid } \\
\text { metabolism }\end{array}$ & Q9BKL2 & Hydra attenuata Tight junction protein $\mathrm{ZO}-1$ & 191163 & 42 \\
\hline & Lipid metabolism & Q7Q4L2 & Anopheles gambiae EbiP6538 [fragment] & 245094 & 50 \\
\hline \multirow[t]{8}{*}{ Transport } & & O02384 & Asterias forbesii Ferritin & 19406 & 290 \\
\hline & & Q7M416 & Liolophura japonica Globin-1 & 15501 & 41 \\
\hline & & Q6W981 & $\begin{array}{l}\text { Asterina miniata Sodium/potassium ATPase alpha subunit } \\
\text { [fragment] }\end{array}$ & 45652 & 216 \\
\hline & & P35317 & $\begin{array}{l}\text { Hydra attenuata Sodium/potassium-transporting ATPase } \\
\text { alpha chain }\end{array}$ & 115228 & 195 \\
\hline & & Q7YZC2 & $\begin{array}{l}\text { Crassostrea virginica Multixenobiotic resistance protein } \\
\text { [fragment] }\end{array}$ & 33429 & 131 \\
\hline & & Q7QDU1 & Anopheles gambiae AgCP10635 [fragment] & 80895 & 38 \\
\hline & & Q7QKG6 & Anopheles gambiae AgCP13040 [fragment] & 53909 & 30 \\
\hline & & Q6VQ13 & Apis mellifera $\mathrm{ADP} / \mathrm{ATP}$ translocase & 33193 & 308 \\
\hline \multirow[t]{11}{*}{$\begin{array}{l}\text { Signal } \\
\text { transduction }\end{array}$} & & Q8TA72 & Asterias amurensis Guanylate cyclase & 120283 & 1484 \\
\hline & & O97053 & Stichopus japonicus Membrane guanylyl cyclase & 122880 & 33 \\
\hline & & Q7PTP0 & Anopheles gambiae ENSANGP00000017234 [fragment] & 147985 & 31 \\
\hline & & P23232 & $\begin{array}{l}\text { Loligo forbesi Guanine nucleotide-binding protein subunit } \\
\text { beta }\end{array}$ & 37983 & 51 \\
\hline & & Q6ZXJ1 & $\begin{array}{l}\text { Apis mellifera carnica CAMP-dependent protein kinase } \\
\text { type II regulatory chain }\end{array}$ & 43897 & 38 \\
\hline & & Q7PXF7 & Anopheles gambiae AgCP12176 & 40869 & 53 \\
\hline & & Q7PRA8 & Anopheles gambiae ENSANGP00000010845 [fragment] & 46495 & 38 \\
\hline & & Q9GRJ1 & Lumbricus rubellus Calmodulin & 16699 & 140 \\
\hline & & Q7PNP2 & Anopheles gambiae ENSANGP00000020903 & 23764 & 155 \\
\hline & & Q7QB74 & Anopheles gambiae AgCP2496 [fragment] & 23913 & 33 \\
\hline & & Q6PPH1 & Homalodisca coagulata Putative rab11 & 24502 & 33 \\
\hline \multirow[t]{7}{*}{ Others } & & Q7Z0F7 & Moira clotho Bindin [fragment] & 48456 & 102 \\
\hline & & Q9XYD5 & Haemonchus contortus Transposase homolog & 39731 & 31 \\
\hline & & Q8MQH7 & Strongylocentrotus purpuratus Deadringer-like protein & 56228 & 39 \\
\hline & & Q7PSE5 & Anopheles gambiae ENSANGP00000022464 [fragment] & 29953 & 65 \\
\hline & & Q26457 & Aedes albopictus La protein homolog & 44460 & 31 \\
\hline & & Q8WRV0 & Meloidogyne incognita 14-3-3 product & 29804 & 120 \\
\hline & & Q94509 & $\begin{array}{l}\text { Dirofilaria immitis Neurotrophil chemotactic factor } \\
\text { [fragment] }\end{array}$ & 53392 & 39 \\
\hline \multirow[t]{6}{*}{ Unknown } & & Q7Q1Q4 & Anopheles gambiae AgCP8854 [fragment] & 23771 & 97 \\
\hline & & Q7QCD5 & Anopheles gambiae AgCP1515 [fragment] & 30235 & 43 \\
\hline & & Q7QKJ9 & Anopheles gambiae AgCP14237 & 29816 & 38 \\
\hline & & Q7Q4B6 & Anopheles gambiae EbiP6697 [fragment] & 135933 & 40 \\
\hline & & Q7QM92 & Anopheles gambiae EbiP2 [fragment] & 35464 & 37 \\
\hline & & Q7QNJ0 & Anopheles gambiae EbiP30 [fragment] & 36813 & 48 \\
\hline
\end{tabular}




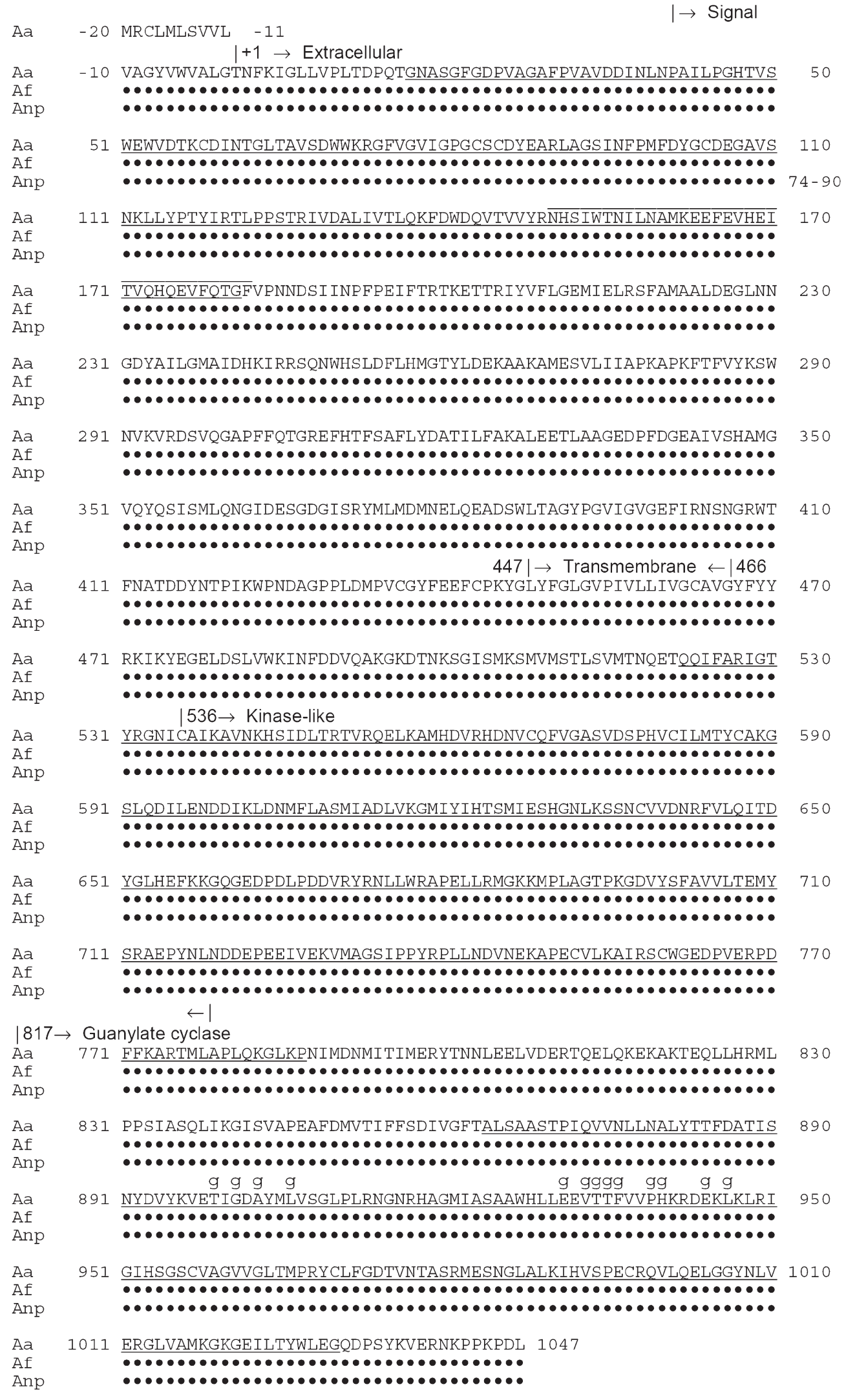

Figure S1. Distribution of peptides identified by mass spectrometry. The amino acid sequence of the entire guanylate cyclase of Asterias amurensis (Aa) is shown at the top. The peptides identified are colored in red for Aa, blue for A. forbesi (Af), and magenta for Asterina pectinifera (Anp). The mature protein starts at the residue +1 . The name of each domain, which starts at $\mid \rightarrow$ and ends at $\leftarrow \mid$, is indicated above (see also Fig. $4 \mathrm{~A}$ ). The parts of the Aa sequence subjected to the homology modeling are underlined. A potential ligand-binding region is noted by a line over the region. Potential GTP binding sites in the guanylate cyclase domain are marked by g above the sequence. 